\title{
Ablative laser surgery for allergic tattoo reactions: a retrospective study
}

\author{
S. A. S. van der Bent ${ }^{1} \cdot$ Sanne Huisman ${ }^{1}$ (D) $\cdot$ T. Rustemeyer $^{1} \cdot$ A. Wolkerstorfer ${ }^{1}$
}

Received: 16 April 2020 / Accepted: 15 October 2020 / Published online: 26 October 2020

(C) The Author(s) 2020

\begin{abstract}
Patients with allergic tattoo reactions are burdened with itch and have a reduced quality of life. Conservative treatment is often insufficient and little is known about treatment options to remove the responsible allergen. We aimed to address the effectiveness and safety of ablative laser therapy including measurement of patient's satisfaction, in patients with allergic reactions to tattoos. A retrospective study was conducted including patients with allergic tattoo reactions who were treated with a 10,600 nm ablative $\mathrm{CO}_{2}$ laser, either by full-surface ablation or fractional ablation. Clinical information originated from medical files and a 25 -item questionnaire. Sixteen tattoo allergy patients were treated with a $\mathrm{CO}_{2}$ laser between January 2010 and January 2018. Fourteen patients completed the questionnaire. Ten patients were satisfied with laser treatment. On a visual analogue scale, pruritus and burning improved with a median of 5.5 and 4 points in the full surface ablation group and 3 points on both parameters in the fractional ablation group. Despite the relatively small group of patients, our results suggest that $\mathrm{CO}_{2}$ laser ablation improves itching, burning and impact on daily life in tattoo allergy.
\end{abstract}

Keywords Red tattoo $\cdot$ Contact dermatitis $\cdot$ Ablative laser $\cdot \mathrm{CO}_{2}$ laser $\cdot$ Patient-reported outcome

\section{Introduction}

Tattooing is a worldwide popular form of body art with an overall prevalence in Europe and the USA of approximately $10-20 \%$ [1]. Although it is regarded safe, adverse reactions may occur, including allergic reactions. Many dyes are used for tattooing, but the red dye is most frequently associated with allergic reactions [2, 3]. These reactions are chronic and persistent, characterised by itch, burning and pain and can develop months to many years after getting a tattoo. Regardless of size and location of the affected area, allergic reactions can result in a significantly reduced quality of life [4]. Several clinical subtypes can be recognised of which the 'plaque type' is most common. Other, less common types are the 'excessive hyperkeratotic reaction' or the 'ulcero-necrotic reaction' $[5,6]$. Thus far, the responsible allergens have not

Sanne Huisman

sanne_huisman@icloud.com

1 Academic Tattoo Clinic Amsterdam, Department of Dermatology, Amsterdam University Medical Centre, Location AMC, Meibergdreef 9, 2205 AZ Amsterdam, The Netherlands been identified and the exact patho-mechanism remains unknown [7-9].

Treatment of these allergic reactions is difficult, as tattoo pigments are permanently stored in the dermis. Topical or intralesional corticosteroids are indicated as first-line treatment but effects are often temporary and unsatisfactory [10]. Allopurinol was reported to be effective in one patient; however, symptoms recurred after withdrawal of the drug [11]. Likewise, hydroxychloroquine caused complete regression of pseudolymphomatous tattoo reaction on the trunk and a granulomatous reaction to a red cosmetic tattoo $[12,13]$. To achieve permanent remission, the causative allergen needs to be removed. However, the best treatment option to remove the responsible allergen is unknown. Surgical excision, dermatome shaving, Q-switched lasers and ablative $\mathrm{CO}_{2}$ lasers are reported as treatment options with permanent results [14, 15]. Nevertheless, each treatment option has its disadvantages, such as possible scarring, infection, risk of generalised allergic reactions and treatment imprecision.

Millán Cayetano et al. considered the continuous wave $\mathrm{CO}_{2}$ laser as an effective, safe and precise treatment for improving red tattoo reactions in six patients [16]. Fractional ablation was effectively and safely used for the removal of allergic tattoo reactions in three patients $[17,18]$. Apart from 
these small studies, clinical efficacy has been studied insufficiently. Furthermore, patient-reported outcome measures (PROMs) have not been thoroughly investigated in this field. PROMs are crucial as quality of life and symptom reduction are best assessed by patients themselves [19]. The aim of this study was to report real-life data using ablative laser treatment and to assess PROMs regarding the effectiveness and safety of ablative $\mathrm{CO}_{2}$ laser treatment for allergic tattoo reactions.

\section{Material and methods}

We performed a retrospective study in which we included patients with allergic tattoo reactions treated with the $10,600 \mathrm{~nm}$ ablative $\mathrm{CO}_{2}$ laser (Lumenis Ultrapulse Encore, Lumenis Ltd., Santa Clara, CA, USA) using a handpiece for full surface ablation ( $2 \mathrm{~mm}$ true spot) and/or a handpiece for fractional ablation (DeepFx handpiece, $120 \mu \mathrm{m}$ beam diameter). Patients were treated between January 2010 and December 2017.

Patients were eligible for inclusion if clinically an allergic reaction was diagnosed and if they were treated with the ablative $\mathrm{CO}_{2}$ laser. Allergic tattoo reactions were defined as chronic inflammatory reactions, manifesting in one single colour and persisting for at least 3 months $[5,19]$. As there are currently no routine patch tests, the distinction between an allergic tattoo reaction, sarcoidosis and foreign body reaction is mostly clinical (the allergic tattoo reaction is localised to one specific colour) $[20,21]$. Furthermore, the histopathology of allergic tattoo reactions is frequently granulomatous as well [22]. Nevertheless, if histologically a granulomatous reaction was observed, laboratory test (including $\mathrm{ACE}$ and in some cases sIL-2R) and chest X-ray were performed to exclude sarcoidosis.

Based on the clinical information provided by the physician, patients and physician made a shared decision about the preferred treatment, either fractional or full surface ablation.

All patients received a test treatment 3 months before the full treatment was started to assess effectiveness and cosmetic outcomes on a small test area.

All patients received infiltration anaesthesia (lidocaine $2 \%$ + adrenaline 1:80000).

Fractional ablation settings ranged from 25 to $40 \mathrm{~mJ} /$ microbeam and $15-25 \%$ density. Full surface ablation was performed with a $2 \mathrm{~mm}$ spot, $225 \mathrm{~mJ}$ and $10-30 \mathrm{~W}$ combined with wet gauzes to remove carbonised tissue between laser passes. The clinical endpoint of the full surface ablation was the complete removal of red pigments.

After fractional ablation, patients received fucidic acid $20 \mathrm{mg} / \mathrm{g}$ cream twice daily for 1 week. After full surface ablation, patients received silver sulfadiazine $10 \mathrm{mg} / \mathrm{g}$ cream under hydrofibre absorbent dressings for 1 week. After 1 week when the dressings were removed, patients applied silver sulfadiazine $10 \mathrm{mg} / \mathrm{g}$ cream twice daily until healing of the wound was observed. In the case of large areas treated with full surface ablation, systemic antibiotics were used.

Clinical information was obtained from patient's records and a 25 -question questionnaire, addressing 3 topics. The questionnaire was performed retrospectively in December 2017 and January 2018. Overall primary endpoint was patient satisfaction. The questionnaire focused on 3 topics: clinical baseline information, symptoms and outcomes.

\section{Clinical baseline information}

Time interval between placement of tattoo and complaints and, previous treatments. The time interval was based on an ordinal scale. Previous treatment options were given and could be answered with either yes or no. If patients received previous treatment, effects were analysed on an ordinal scale (from no effect to excellent effect).

\section{Symptoms}

Subjective symptoms before and after laser therapy, such as itch and burning. These questions were based on a visual analogue scale (VAS, $0-10$ ), with 0 meaning no itch or burning and 10 meaning the worst itch or burning.

\section{Outcomes}

Overall satisfaction, cosmetic outcome and satisfaction with improvement of pruritus, burning, inflammation and influence on daily life were based on an ordinal scale (from highly unsatisfied to highly satisfied). Evaluation of pain and discomfort during treatment was based on a VAS $(0-10)$, with 0 meaning no pain or discomfort and 10 meaning the worst pain or discomfort. Scar formation and pigment variation could be answered with either yes or no. If present, the burden of scars and pigment variation were based on a VAS $(0-10)$, with 0 meaning no burden and 10 meaning the worst burden.

A statistical analysis was performed. Outcomes between groups were compared using the Student's $t$ test, MannWhitney $U$ test or Kruskall-Wallis test depending on distribution and the number of groups. Categorical data was compared using the chi2 test or Fisher's exact test depending on group sizes.

\section{Results}

\section{Patient characteristics}

Sixteen patients ( 11 women, 5 men) were treated with an ablative $\mathrm{CO}_{2}$ laser. Two patients were first treated with the 
fractional $\mathrm{CO}_{2}$ laser without clinical improvement and were therefore also treated with full surface ablation. Therefore, 10 patients were treated with the fractional $\mathrm{CO}_{2}$ laser and 8 patients were treated with the fullsurface $\mathrm{CO}_{2}$ laser.

The median age was 44.5 years. Red or nuances of red made up for $94 \%$ of all responsible pigments. Other patient characteristics are shown in Table 1.

All patients had received prior treatment, such as topical and/or intralesional corticosteroids and Q-switched laser therapy. Prior treatment either failed or patients desired a more permanent solution.
The number of sessions needed varied between both groups, with a median of 1 in the full-surface $\mathrm{CO}_{2}$ laser group and a median of 4 in the fractional $\mathrm{CO}_{2}$ laser group $(P<001)$.

\section{Results from medical files}

The medical files indicated complete remission of symptoms, such as itching, burning or swelling, in six patients $(33.3 \%)$, which was maintained until the last follow-up. Nine patients had partial remission (50\%) and maintained occasional itching or burning. Potent topical corticosteroids were prescribed in
Table 1 Baseline characteristics of 18 treatments in 16 patients

\begin{tabular}{|c|c|c|c|}
\hline & All $(n=18)$ & $\begin{array}{l}\text { GROUP A (full } \\
\text { surface } \\
\text { ablation) }(n=8)\end{array}$ & $\begin{array}{l}\text { GROUP B } \\
\text { (fractional } \\
\text { ablation) }(n=10)\end{array}$ \\
\hline \multicolumn{4}{|l|}{ Age (years) } \\
\hline Median [Q1-Q3] & $\begin{array}{l}44.5 \\
\quad[36-52.25]\end{array}$ & $44.5[36.25-57.75]$ & $44.5[35.75-52.25]$ \\
\hline \multicolumn{4}{|l|}{ Gender, $n$} \\
\hline Male & 6 & 5 & 7 \\
\hline Female & 12 & 3 & 3 \\
\hline \multicolumn{4}{|l|}{$\begin{array}{l}\text { Time between placement } \\
\text { of tattoo and complaints, } n\end{array}$} \\
\hline$<2$ weeks & 7 & 2 & 5 \\
\hline$>2-<4$ weeks & 3 & 2 & 1 \\
\hline$>1-<3$ months & 3 & 2 & 1 \\
\hline$>3-<6$ months & 4 & 2 & 2 \\
\hline$>6-<12$ months & 0 & 0 & 0 \\
\hline$>12$ months & 1 & 0 & 1 \\
\hline \multicolumn{4}{|l|}{ Histopathological pattern, $n$} \\
\hline Pseudolymphomatous & 4 & 4 & 0 \\
\hline Granulomatous & 4 & 2 & 2 \\
\hline Pseudolymphomatous/granulomatous & 1 & 1 & 0 \\
\hline Not avalaible & 9 & 1 & 8 \\
\hline \multicolumn{4}{|l|}{ Location, $n$} \\
\hline Lower leg/ankle & 12 & 6 & 6 \\
\hline Upper leg & 1 & 0 & 1 \\
\hline Forearm & 3 & 1 & 2 \\
\hline Upper arm & 2 & 1 & 1 \\
\hline \multicolumn{4}{|l|}{ Colour, $n$} \\
\hline Red & 17 & 7 & 10 \\
\hline Black & 1 & 1 & 0 \\
\hline \multicolumn{4}{|l|}{ Previous treatment, $n$} \\
\hline Potent topical corticosteroids & 6 & 1 & 5 \\
\hline $\begin{array}{l}\text { Potent topical and intralaesional } \\
\text { corticosteroids }\end{array}$ & 7 & 5 & 2 \\
\hline Intralesional corticosteroids & 3 & 1 & 2 \\
\hline $\begin{array}{l}\text { Potent topical corticosteroids and other laser } \\
\text { treatment }\end{array}$ & 2 & 1 & 1 \\
\hline
\end{tabular}

Q1-Q3 interquartile range 
Table 2 Results from medical files, not patient reported

\begin{tabular}{llll}
\hline & All $(n=18)$ & GROUP A (full surface ablation) $(n=8)$ & GROUP B (fractional ablation) $(n=10)$ \\
\hline $\begin{array}{l}\text { Number of sessions } \\
\text { Median [Q1-Q3] }\end{array}$ & $2.5[1-4.25]$ & $1[1-1.75]$ & $4[3-6.25]$ \\
$\begin{array}{l}\text { Follow-up (months) } \\
\text { Median [Q1-Q3] }\end{array}$ & $14[9.25-39.75]$ & $8.5[4.75-11.75]$ & $31[20.5-60]$ \\
$\begin{array}{l}\text { Result after treatment, } n(\%) \\
\text { Complete remission }\end{array}$ & $6(33.3)$ & $3(37.5)$ & \\
Partial remission & $9(50)$ & $4(50)$ & $3(30)$ \\
No improvement & $3(16.7)$ & $1(12.5)$ & $5(50)$ \\
\hline
\end{tabular}

some patients to control these residual symptoms. Results of medical files are shown in Table 2 (Figs. 1, 2 and 3).

Two adverse events were reported. One patient with skin type 4 developed a keloidal scar after full surface ablation on his upper arm. The other patient developed a generalised allergic reaction 1 day after the fifth fractional $\mathrm{CO}_{2}$ laser treatment. Eczema developed around the tattoo, on the arms, face and knees. She was treated with oral antihistamines and topical potent corticosteroids resulting in gradual improvement of the eczematous reaction. This case was reported previously [18].

\section{Patient-reported outcomes}

Two patients did not complete the questionnaire. Thus, 14 patients responded (88\%). PROMs are shown in Table 3. From the responding patients, ten patients reported to be either satisfied or highly satisfied with ablative laser treatment $(62.5 \%)$. Six patients reported to be satisfied with the cosmetic aspect after ablative laser treatment (37.5\%), 4 patients were neutral $(25 \%), 6$ patients were unsatisfied or highly unsatisfied $(37.5 \%)$.

Patients rated pain and discomfort of ablative laser therapy with a median VAS score of 3 on both parameters $(P=0.67$ and 0.83 , respectively for pain and discomfort).

Scar formation was reported in 6 patients in the full surface ablation group and 5 patients in the fractional ablation group $(P=1.00)$. Variation in pigment was reported in 7 patients in the full surface ablation group and 4 patients in the fractional ablation group $(P=0.28)$.

Common complaints before starting laser treatment were a burning sensation (93\%) and pruritis (100\%). Improvement on a VAS scale (0-10) was found, for both, burning sensation and pruritis. When comparing improvement of itch and burning between the full surface ablation group (median of 5.5 for itch and 4 for burning) and fractional ablation group (median of 3 for both itch and burning), it should be noted that more improvement was observed in full surface ablation. However, the difference is not statistically significant $(P=0.71$ and 0.91 , respectively for itch and burning).

The vast majority of the full surface ablation group would recommend this therapy to others $(87.5 \%)$, in the fractional ablation group 4 patients $(50 \%)$ gave a recommendation $(P=$ 0.28).

\section{Discussion}

Patients suffering from allergic tattoo reactions are burdened with chronic itch and discomfort [4]. Treatment is challenging. Topical or intralesional corticosteroids are convenient options; however, effectiveness varies and is frequently temporary or insufficient. A safe treatment modality with permanent results is needed. Removal of all culprit pigment by surgery or laser ablation is thought to be the best approach. However, there are variable techniques to remove the pigments and little

Fig. 1 Before and after of a red tattoo reaction treated with fractional ablation

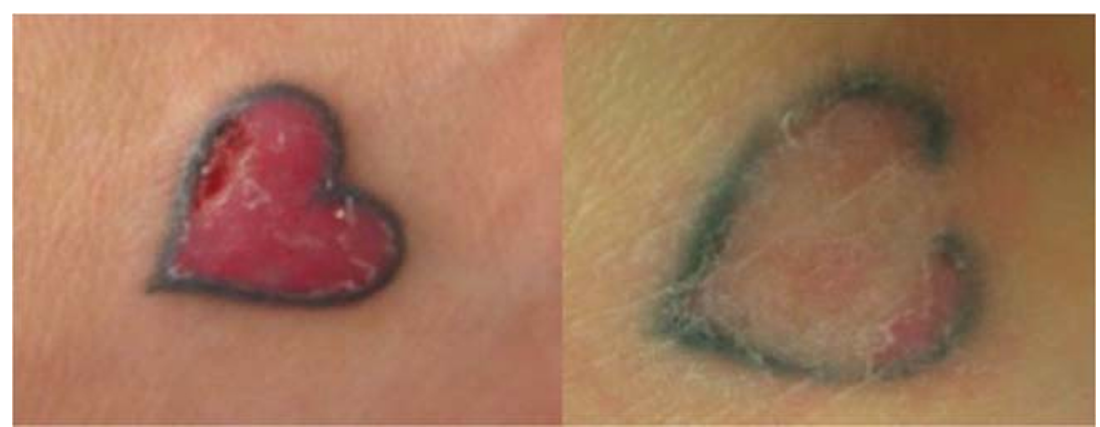


Fig. 2 A red tattoo reaction ('plaque type') during treatment with fractional ablation

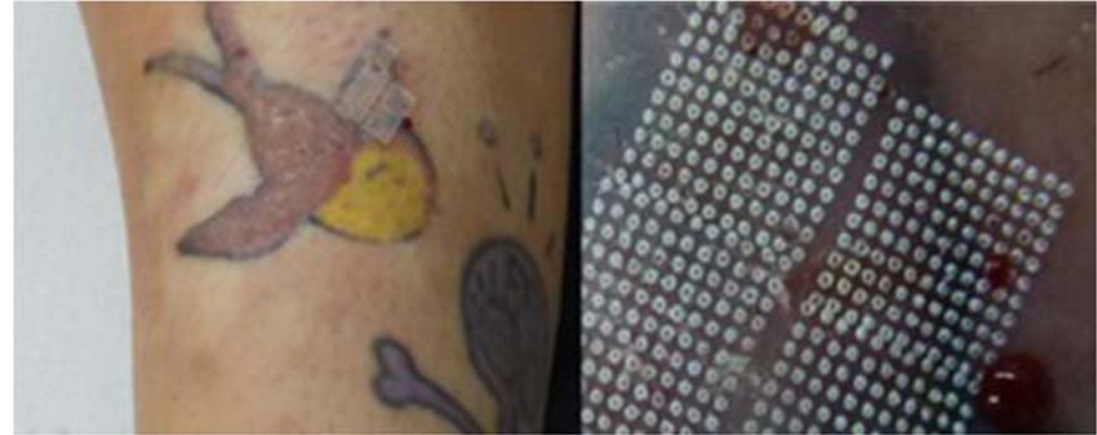

is known about efficacy, side effects and PROMs. In our study, we found that $\mathrm{CO}_{2}$ laser therapy can improve the symptoms of allergic tattoo reactions when topical or intralesional corticosteroids are insufficiently effective. Six allergic tattoo reactions showed complete remission $(33.3 \%)$, 9 showed partial remission $(50 \%)$ and 3 lesions showed no improvement (16.7\%) after a median follow-up of 14 months. Remarkably, in some cases with satisfactory outcomes, we observed some residual red pigment questioning the necessity of complete removal of pigment.

\section{Fractional and full surface ablation}

Patients were overall satisfied with the treatment and reported marked improvement of their symptoms. When comparing our treatment groups, more improvement was reported in the full surface ablation group. Fractional ablation is less invasive with less side effects in comparison to full surface ablation, however, at the cost of multiple treatments and possibly lower efficacy. The difference could not be significantly confirmed. Because of this, the study design and the relatively small group of patients, it cannot be concluded that full surface ablation is superior in effectiveness to fractional ablation.

\section{Adverse events}

It should be noted that adverse effects, such as scarring and allergic reactions, may occur. Full surface ablation has a higher risk of scarring compared to fractional ablation [16]. This could be explained by the fact that conventional $\mathrm{CO}_{2}$ lasers ablate the full surface of the skin, whilst fractional $\mathrm{CO}_{2}$ lasers ablate a fraction of the skin at a time by emitting microbeams that create microthermal ablation and coagulation zones leaving unaffected tissue around these zones. In our study, no significant difference in scarring between both groups was observed.

In one patient a generalised eczematous allergic reaction was observed after fractional ablation, treated in our Academic Tattoo Clinic. More cases of generalised allergic reactions after fractional laser therapy to treat allergic tattoo reactions have been reported $[18,23]$. We assume that full surface ablation completely eliminates pigment-containing cells, thereby preventing systematic uptake. However, in fractional ablation, the ablative channels are small and surrounded by coagulation zones which may be responsible for systemic uptake of allergens [18]. In addition, dyspigmentation is reported several times.

\section{Other treatment options}

Other surgical treatment options are conventional fullthickness excision and dermatome shaving. Conventional excision is only favourable in certain anatomical locations and small size tattoos. In addition, scarring is inevitable. Dermatome shaving is an excellent permanent treatment option. However, in this procedure an experienced plastic surgeon or dermatologist is crucial. Furthermore, in our opinion,
Fig. 3 Before and after of a red tattoo reaction ('plaque type') on the wrist treated with full surface ablation

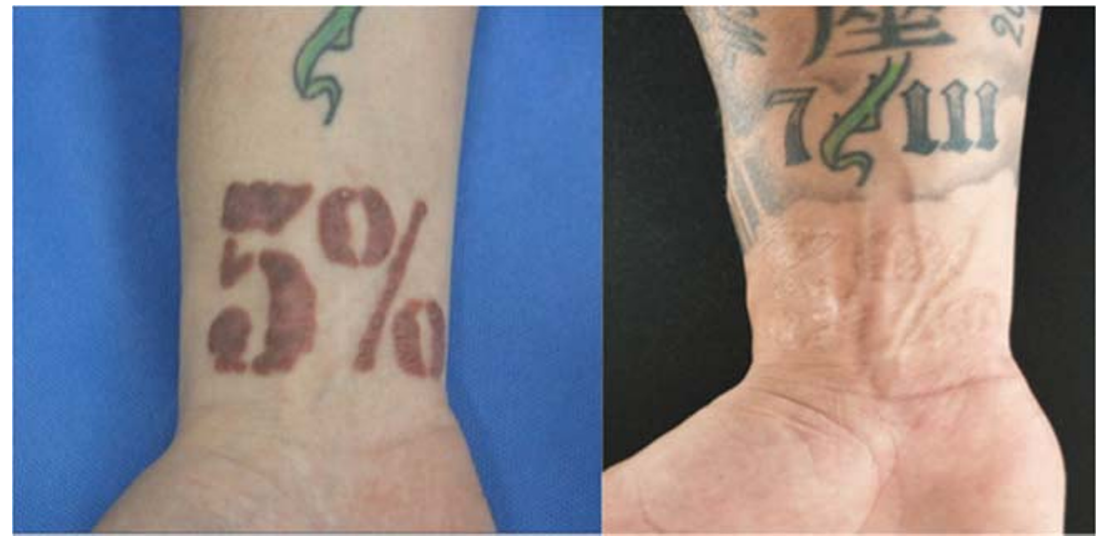


Table 3 Patient-reported outcome of 16 treated tattoos in 14 patients

\begin{tabular}{|c|c|c|c|c|}
\hline & $\begin{array}{l}\text { All } \\
(n=16)\end{array}$ & $\begin{array}{l}\text { GROUP A (full surface } \\
\text { ablation) }(n=8)\end{array}$ & $\begin{array}{l}\text { GROUP B (fractional } \\
\text { ablation) }(n=8)\end{array}$ & $\begin{array}{l}P \\
\text { value }\end{array}$ \\
\hline \multicolumn{5}{|l|}{ Satisfaction with } \\
\hline \multicolumn{4}{|l|}{ Laser treatment, $n(\%)$} & \multirow[t]{6}{*}{0.45} \\
\hline Highly satisfied & $3(18.8)$ & $2(25)$ & $1(12.5)$ & \\
\hline Satisfied & $7(43.8)$ & $4(50)$ & $3(37.5)$ & \\
\hline Neutral & $3(12.5)$ & 0 & $3(37.5)$ & \\
\hline Unsatisfied & $2(12.5)$ & $1(12.5)$ & $1(12.5)$ & \\
\hline Highly unsatisfied & $1(6.3)$ & $1(12.5)$ & 0 & \\
\hline \multicolumn{4}{|l|}{ Cosmetic aspect, $n(\%)$} & \multirow[t]{6}{*}{0.59} \\
\hline Highly satisfied & 0 & 0 & 0 & \\
\hline Satisfied & $6(37.5)$ & $4(50)$ & $2(25)$ & \\
\hline Neutral & $4(25)$ & $1(12.5)$ & $3(37.5)$ & \\
\hline Unsatisfied & $3(18.8)$ & $2(25)$ & $1(12.5)$ & \\
\hline Highly unsatisfied & $3(18.8)$ & $1(12.5)$ & $2(25)$ & \\
\hline \multicolumn{4}{|c|}{ Improvement itch and burning, $n(\%)$} & \multirow[t]{6}{*}{0.93} \\
\hline Highly satisfied & $4(25)$ & $3(37.5)$ & $1(12.5)$ & \\
\hline Satisfied & $2(12.5)$ & $1(12.5)$ & $1(12.5)$ & \\
\hline Neutral & $2(12.5)$ & $1(12.5)$ & $1(12.5)$ & \\
\hline Unsatisfied & $4(25)$ & $1(12.5)$ & $3(37.5)$ & \\
\hline Highly unsatisfied & $4(25)$ & $2(25)$ & $2(25)$ & \\
\hline \multicolumn{4}{|c|}{ Improvement inflammation, $n(\%)$} & \multirow[t]{6}{*}{0.52} \\
\hline Highly satisfied & $3(18.8)$ & $2(25)$ & $1(12.5)$ & \\
\hline Satisfied & $6(37.5)$ & $3(37.5)$ & $3(37.5)$ & \\
\hline Neutral & $2(12.5)$ & 0 & $2(25)$ & \\
\hline Unsatisfied & $3(18.8)$ & $1(12.5)$ & $2(25)$ & \\
\hline Highly unsatisfied & $2(12.5)$ & $2(25)$ & 0 & \\
\hline \multicolumn{5}{|l|}{ Evaluation of laser therapy } \\
\hline Pain (median [Q1-Q3])* & $3[1.25-5]$ & $3[2.25-4.5]$ & $3.5[0.25-5]$ & 0.67 \\
\hline $\begin{array}{l}\text { Discomfort (median } \\
\text { [Q1-Q3])* } \\
\text { Adverse effects }\end{array}$ & $3[1-5]$ & $2.5[1.25-3.75]$ & $3.5[0.25-5.75]$ & 0.83 \\
\hline Scars, $n(\%)$ & $11(68.8)$ & $6(75)$ & $5(62.5)$ & 1.00 \\
\hline $\begin{array}{l}\text { Level of inconvenience } \\
\text { (median [Q1-Q3])* }\end{array}$ & $\begin{array}{l}2.5 \\
{[1-6.75]}\end{array}$ & $2.5[0.75-7.75]$ & $5[0.5-7]$ & 1.00 \\
\hline Variation in pigment, $n(\%)$ & $11(68.8)$ & $7(87.5)$ & $4(50)$ & 0.28 \\
\hline $\begin{array}{l}\text { Level of inconvenience } \\
\text { (median [Q1-Q3])* } \\
\text { Improvement of symptoms }\end{array}$ & $4[1-5]$ & $4[0-7]$ & $4.5[1.75-5]$ & 0.92 \\
\hline Itch (median [Q1-Q3])* & $\begin{array}{l}4.5 \\
\quad[7.75-0- \\
.25]\end{array}$ & $5.5[8-0]$ & $3[7.25-0.25]$ & 0.71 \\
\hline Burning (median [Q1-Q3])* & $4[7-0]$ & $4[7-0]$ & $3[7.75-0.75]$ & 0.91 \\
\hline $\begin{array}{l}\text { Influence on daily life } \\
(\text { median [Q1-Q3])* }\end{array}$ & $2[4-0]$ & $3[4-0]$ & $2[3.75-0.25]$ & 1.00 \\
\hline Recommendation, $n(\%)$ & $11(68.8)$ & $7(87.5)$ & $4(50)$ & 0.28 \\
\hline
\end{tabular}

Q1-Q3 = interquartile range

* Registered upon a continuous rating scale from 0 to 10 , with 0 being no harm and 10 being extreme harm
$\mathrm{CO}_{2}$ lasers have the possibility of treating more accurately in a horizontal plane, resulting in better preservation of the original tattoo design. The pigment-loaded tissue can be removed layer by layer until the desired endpoint, removal of pigment, is achieved. As the depth of the tattoo inks in the skin differs, it is an advantage that depth of laser treatment can be adjusted. 
Dermatome shaving may also elicit complications such as scarring, hyper- and hypo-pigmentation, which required additional treatments with intralesional corticosteroids in almost $20 \%$ to control scarring [14]. Furthermore, in contrary to dermatome shaving, ablative laser therapy is not a bloody procedure due to surrounding coagulation. Experienced laser surgeons can take advantage of this phenomenon and vary the ratio between ablation and coagulation by adjusting the pulse energy. Therefore, the risk of post-procedure bleeding is smaller.

Another treatment option for allergic tattoo reactions is the Q-switched laser. Unlike ablative lasers, Q-switched lasers are the gold standard for removal of uncomplicated tattoos [24]. Q-switched lasers selectively damage pigment-containing cells, after which pigment particles are released into the systemic circulation. The photomechanical breakdown of pigments may also produce and systemically spread new allergens and harmful chemicals. Several cases of localised, generalised and even anaphylactic allergic reactions have been reported following Q-switched laser tattoo removal in patients with a pre-existent allergic reaction to tattoo pigments or even in prior non-allergic patients [25-28]. Besides the risk of inducing systemic allergic reactions, treatment efficacy for allergic tattoo reactions to red pigment with a Q-switched-laser is compromised because of the limited penetration depth at $532 \mathrm{~nm}$, whilst in 'plaque reactions', an evident thickening arises with deeply located pigments. Moreover, Q-switched lasers may require more than ten treatments.

Thus far, this is the largest study of ablative laser therapy in allergic tattoo reactions. Another strength of this study is the long follow-up and the presence of real-life data. Limitations of this study are its retrospective nature, the limited number of included patients and the descriptive analysis. Also, patients were not laser naïve. The response rate of the questionnaire was $88 \%$, which is high. However, it should be noted that some patients had to assess their clinical symptoms years after the initial diagnosis and treatment.

Unfortunately, two patients were lost to follow-up. Furthermore, no validated outcome measures could be used due to a lack of research in this field. Future research should be prospective and include an objective evaluation of improvement of skin inflammation.

Despite the relatively small group of patients, our results suggest that $\mathrm{CO}_{2}$ laser ablation (either fractional or full surface ablation) improves itching, burning and impact on daily life in tattoo allergy. It may be implemented as third-line treatment, when topical or intralesional corticosteroids are insufficiently effective. Patients seem to prefer the full surface ablation above fractional ablation, which may result from higher effectiveness and less treatment sessions. However, this could not be statistically confirmed. Patients should be thoroughly informed about the possible risks, especially scar and keloid formation. More evidence is needed before final recommendations can be given.

\section{Compliance with ethical standards}

Conflict of interest No conflict of interest.

Ethical approval All included patients gave their written informed consent and the study protocol was approved by the institute's committee on human research.

Open Access This article is licensed under a Creative Commons Attribution 4.0 International License, which permits use, sharing, adaptation, distribution and reproduction in any medium or format, as long as you give appropriate credit to the original author(s) and the source, provide a link to the Creative Commons licence, and indicate if changes were made. The images or other third party material in this article are included in the article's Creative Commons licence, unless indicated otherwise in a credit line to the material. If material is not included in the article's Creative Commons licence and your intended use is not permitted by statutory regulation or exceeds the permitted use, you will need to obtain permission directly from the copyright holder. To view a copy of this licence, visit http://creativecommons.org/licenses/by/4.0/.

\section{References}

1. Kluger N (2015) Epidemiology of tattoos in industrialized countries. Curr Probl Dermatol 48:6-20

2. De Cuyper C (2009) Cosmetic and medical applications of tattooing. In: Cuyper CD, Pérez-Cotapos SML (eds) Dermatologic Complications with Body Art. Springer, Berlin

3. Van der Bent SA, Wolkerstorfer A, Rustemeyer T (2016) Cutaneous adverse reactions to tattoos. Ned Tijdschr Geneeskd 160:A9808

4. Hutton Carlsen K, Serup J (2014) Patients with tattoo reactions have reduced quality of life and suffer from itch. Skin Res Technol 21:101-107

5. Serup J, Carlsen KH, Sepehri M (2015) Tattoo complaints and complications: diagnosis and clinical spectrum. Curr Probl Dermatol 48:48-60

6. Van der Bent SAS, Maijer KI, Rustemeyer T (2017) Image gallery: hyperkeratotic hypersensitivity reaction to red pigment tattoo. $\mathrm{Br} \mathrm{J}$ Dermatol 177:e350

7. Serup J, Hutton CK (2014) Patch test study of 90 patients with tattoo reactions: negative outcome of allergy patch test to baseline batteries and culprit inks suggests allergen(s) are generated in the skin through haptenization. Contact Dermatitis 71:255-263

8. Bil W, van der Bent SAS, Spiekstra SW, Nazmi K, Rustemeyer T, Gibbs S (2018) Comparison of the skin sensitization potential of 3 red and 2 black tattoo inks using interleukin-18 as a biomarker in a reconstructed human skin model. Contact Dermatitis 79:336-345

9. Van der Bent SAS, de Winter RW, Wolkerstorfer A, Rustemeyer T (2019) Red tattoo reactions, a prospective cohort on clinical aspects. J Eur Acad Dermatol Venereol 33(10):e384-e386

10. Wambier CG, Cappel MA, Wambier SPF (2017) Treatment of reaction to red tattoo ink with intralesional triamcinolone. An Bras Dermatol 95:748-750

11. Godinho MM, Aguinaga F, Grynszpan R, Lima VM, Azulay DR, Cuzzi T, Ramos-E-Silva M, Manela-Azulay M (2015) Granulomatous reaction to red tattoo pigment treated with allopurinol. J Cosmet Dermatol 14:241-245

12. Patrizi A, Raone B, Savoia F, Bacci F, Pileri A, Gurioli C, Neri I (2009) Tattoo-associated pseudolymphomatous reaction and its successful treatment with hydroxychloroquine. Acta Derm Venereol 89(3):327-328 
13. De Winter RW, van der Bent SAS, van Esch M, Wolkerstorfer A, Rustemeyer T (2019) Allergic reaction to red cosmetic lip tattoo treated with hydroxychloroquine. Dermatitis. 30(1):82-83

14. Sepehri M, Jørgensen B, Serup J (2015) Introduction of dermatome shaving as first line treatment of chronic tattoo reactions. J Dermatolog Treat 26:451-455

15. Forbat E, Al-Niaimi F (2016) Patterns of reactions to red pigment tattoo and treatment methods. Dermatol Ther 6:13-23

16. Millán-Cayetano JF, Alegre-Sánchez A, Boixeda P (2017) Treatment of red tattoo reactions using $\mathrm{CO}_{2}$ laser. Lasers Med Sci 33(5):1171-1173

17. Ibrahimi OA, Syed Z, Sakamoto FH, Avram MM, Anderson RR (2011) Treatment of tattoo allergy with ablative fractional resurfacing: a novel paradigm for tattoo removal. J Am Acad Dermatol 64:1111-1114

18. Meesters AA, De Rie MA, Wolkerstorfer A (2016) Generalized eczematous reaction after fractional carbon dioxide laser therapy for tattoo allergy. J Cosmet Laser Ther 18:456-458

19. Prinsen CAC, Mokkink LB, Bouter LM, Alonso J, Patrick DL, de Vet HCW, Terwee CB (2018) COSMIN guideline for systematic reviews of patient-reported outcome measures. Qual Life Res

20. Kluger N (2017) Cutaneous complications related to tattoos: 31 cases from Finland. Dermatology 233(1):100-109

21. Maijer KI, van der Bent SAS, Vercoutere W, Rustemeyer T (2018) Granulomatous tattoo reaction with associated uveitis successfully treated with methotrexate. J Eur Acad Dermatol Venereol 32(9): e338-e339
22. Van der Bent SAS, Oyen EMM, Rustemeyer T, Jaspars EH, Hoekzema R. Histopathology of red tattoo reactions. Am J Dermatopathol Accepted

23. Zemtsov A, Wilson L (1997) $\mathrm{CO}_{2}$ laser treatment causes local tattoo allergic reaction to become generalized. Acta Derm Venereol 77:497

24. Prinz BM, Vavricka SR, Graf P et al (2004) Efficacy of laser treatment of tattoos using lasers emitting wavelengths of $532 \mathrm{~nm}, 755$ $\mathrm{nm}$ and $1064 \mathrm{~nm}$. Br J Dermatol 150:245-251

25. England RW, Vogel P, Hagan L (2002) Immediate cutaneous hypersensitivity after treatment of tattoo with Nd: YAG laser: a case report and review of the literature. Ann Allergy Asthma Immunol 89:215-217

26. Harper J, Losch AE, Otto SG, Zirwas M, Delaney KO, Wakelin JK 3rd. (2010) New insight into the pathophysiology of tattoo reactions following laser tattoo removal. Plast Reconstr Surg 126:313e-314e

27. Ashinoff R, Levine VJ, Soter NA (1995) Allergic reactions to tattoo pigment after laser treatment. Dermatol Surg 21:291-294

28. Yorulmaz A, Onan DT, Artuz F, Gunes R (2015) A case of generalized allergic contact dermatitis after laser tattoo removal. Cutan Ocul Toxicol 34:234-236

Publisher's note Springer Nature remains neutral with regard to jurisdictional claims in published maps and institutional affiliations. 